\title{
Characterization of $\alpha$-Glucosidase Inhibitor/Cyclodextrin Complex Prepared by Freeze-Drying
}

\author{
Yutaka Inoue $(\mathbb{D}$, Sachie Narumi, Akiho Mitsumori, Isamu Murata, and Ikuo Kanamoto \\ Laboratory of Drug Safety Management, Faculty of Pharmacy and Pharmaceutical Sciences, Josai University, 1-1 Keyakidai, \\ Sakado-shi, Saitama 3500295, Japan
}

Correspondence should be addressed to Yutaka Inoue; yinoue@josai.ac.jp

Received 2 February 2018; Accepted 1 April 2018; Published 7 May 2018

Academic Editor: Tetsuya Ozeki

Copyright (C) 2018 Yutaka Inoue et al. This is an open access article distributed under the Creative Commons Attribution License, which permits unrestricted use, distribution, and reproduction in any medium, provided the original work is properly cited.

\begin{abstract}
Miglitol (MT) is an $\alpha$-glucosidase inhibitor with a postmeal blood glucose level lowering effect that is used to treat type 2 diabetes. In addition, $\alpha$-cyclodextrin $(\alpha \mathrm{CD})$ has been reported to inhibit increases in postmeal blood glucose. The aim of this study was to prepare a freeze-dried product (FD) composed of MT and $\alpha \mathrm{CD}$ or $\gamma \mathrm{CD}$ (molar ratio of $\mathrm{MT} / \alpha \mathrm{CD}=1 / 1, \mathrm{MT} / \gamma \mathrm{CD}=1 / 1$ ) and to evaluate the physicochemical properties and biological activity of the FD. The PXRD profile of FD exhibited a halo pattern, and characteristic peaks derived from MT, $\alpha \mathrm{CD}$, and $\gamma \mathrm{CD}$ were not observed. The TG-DTA results for FD indicated an increased weight loss temperature and the absence of an endothermic peak for MT. The NIR absorption spectrum measurement suggested an intermolecular interaction between MT and $\alpha \mathrm{CD}$ or $\gamma \mathrm{CD}$ in the FD. ${ }^{1} \mathrm{H}^{-1} \mathrm{H}$ NOESY NMR spectroscopy $\left(\mathrm{D}_{2} \mathrm{O}\right)$ revealed an intermolecular interaction in the FD. The results of the $\alpha$-glucosidase activity inhibition test and the $\alpha$-amylase activity inhibition test indicated that the FD exhibited the same inhibition rate as MT alone and the effects of MT were not altered by the freeze-drying method.
\end{abstract}

\section{Introduction}

Recently, the incidence of diabetes has increased in developed countries. This has been attributed to smoking, an inadequate diet, and lack of exercise, and diabetes has become a major cause of the increasing death rate [1]. According to the International Diabetes Federation report, the world diabetes population continues to increase and in 2015, 415 million people were suffering from diabetes. For this reason, the treatment of prediabetes by controlling blood glucose at levels lower than that required for a diabetes diagnosis to prevent the development of full blown diabetes has been gaining attention.

Cyclodextrins (CDs) are cyclic dextrins currently used as food additives. Recently, $\alpha \mathrm{CD}$ was reported to lower blood sugar levels. Specifically, $\alpha \mathrm{CD}$ inhibited pancreatic amylase activity [2] and suppressed increases in blood sugar [3]. In addition, CDs solubilize, stabilize, and mask drugs by inclusion in a complex. For example, formulation of an inclusion complex made of itraconazole, a sparingly soluble antifungal agent, and hydroxypropyl- $\beta \mathrm{CD}[4]$ increased the solubilization of the drug. Additionally, formulation of an inclusion complex made of limaprost, a prostaglandin $\mathrm{E}_{1}$ derivative that is unstable to moisture, and $\alpha$-cyclodextrin [5] increased the drug's stability. Further, masking a drug with cyclodextrin decreased the bitter taste of the drug [6].

The currently available $\alpha$-glucosidase inhibitors include acarbose (AB), voglibose (VB), and miglitol (MT). AB, VB, and MT are used as therapeutic agents for type 2 diabetes. Among them, $\mathrm{AB}$ inhibits $\alpha$-amylase and $\alpha$-glucosidase activity. Additionally, VB and MT are widely used clinically because their $\alpha$-glucosidase inhibitory action is stronger than that of $\mathrm{AB}$. In particular, MT is different from the other two drugs and is quickly absorbed in the upper part of the small intestine. This characteristic suppresses the rise in blood glucose level starting $30 \mathrm{~min}$ after a meal and continuing until $2 \mathrm{~h}$ after a meal. MT is particularly effective at inhibiting the increase in blood glucose at $1 \mathrm{~h}$ after meal.

Therefore, this study focused on MT and aimed to develop a formulation that would provide an additive synergistic suppressive effect on blood glucose elevation by forming a complex with $\alpha \mathrm{CD}$. In this report, inclusion 
<smiles>OCCN1C[C@H](O)[C@H](O)[C@H](O)[C@H]1CO</smiles>

(a)

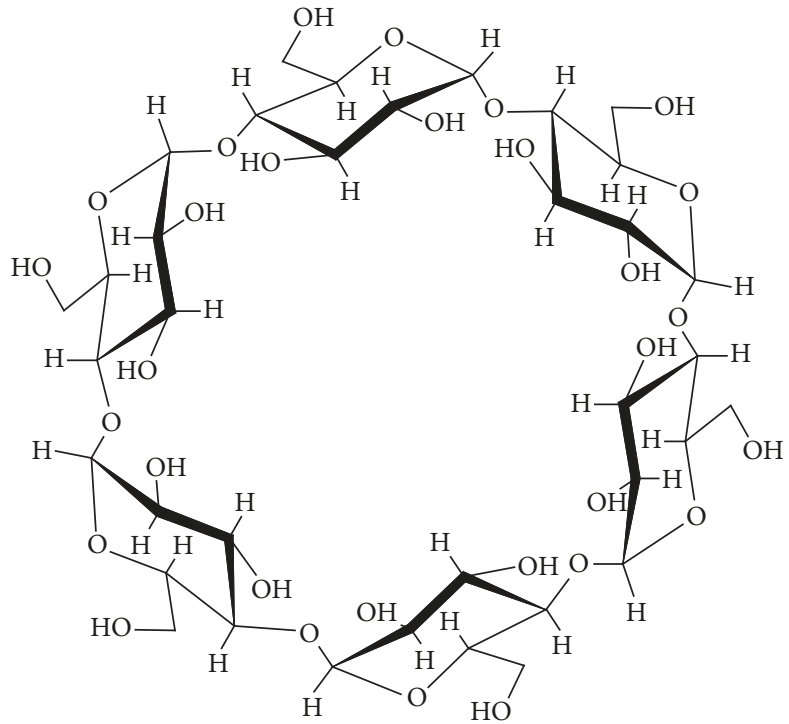

(c)

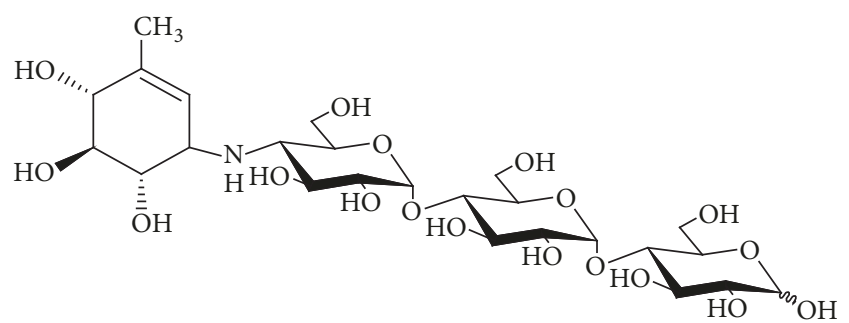

(b)

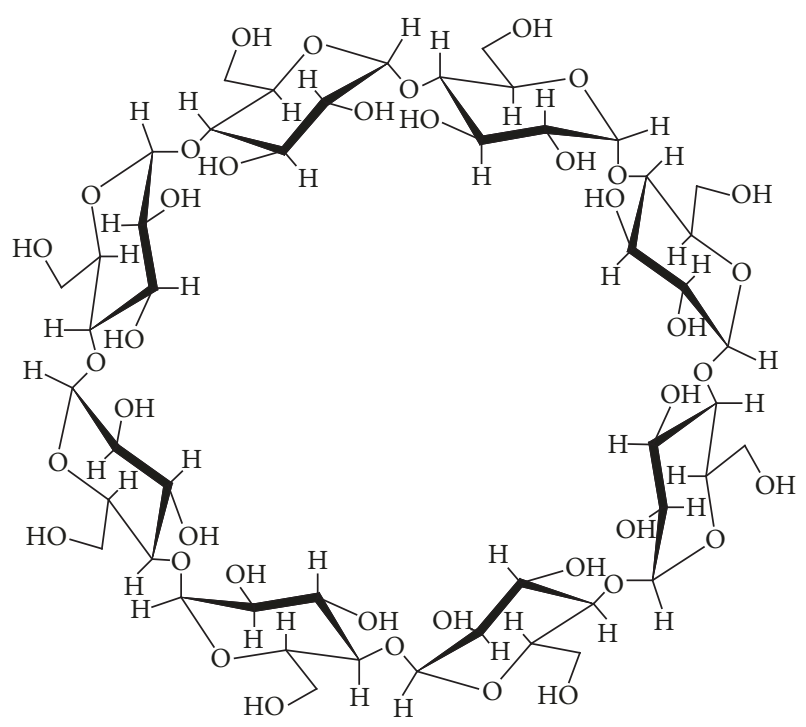

(d)

FIGURE 1: Chemical structures of (a) miglitol, (b) acarbose, (c) $\alpha \mathrm{CD}$, (d) $\gamma \mathrm{CD}$.

complexes with MT were prepared using $\alpha \mathrm{CD}$ and $\gamma \mathrm{CD}$. In addition, the addictive effect of $\alpha \mathrm{CD}$ and $\gamma \mathrm{CD}$ with $\alpha$ glucosidase inhibitors was evaluated.

\section{Materials and Methods}

2.1. Materials. $\alpha \mathrm{CD}$ and $\gamma \mathrm{CD}$ were donated by Cyclo Chem Co., Ltd. (Tokyo, Japan) and stored at a temperature of $40^{\circ} \mathrm{C}$ and relative humidity of $82 \%$ for 7 days before use. MT was donated by SANWA KAGAKU KENKYUSHO Co., Ltd (Figure 1). All other chemicals were of analytical grade and obtained from Wako Pure Chemical Industries., Ltd.

\subsection{Methods}

2.2.1. Preparation of Physical Mixture. A physical mixture (PM) of MT $/ \alpha \mathrm{CD}$ and a PM of MT/ $\gamma \mathrm{CD}$ at a molar ratio of $1 / 1$ was prepared by blending the two compounds for $1 \mathrm{~min}$ using a vortex mixer.

2.2.2. Preparation of Freeze-Dried Product. Complexes were formed using a freeze-drying method. The mixtures prepared with $\mathrm{MT} / \alpha \mathrm{CD}=1 / 1$ and $\mathrm{MT} / \gamma \mathrm{CD}=1 / 1$ were dissolved in $100 \mathrm{~mL}$ of purified water and prefrozen at $-30^{\circ} \mathrm{C}$ or lower. Thereafter, the prefrozen product was freeze-dried in a vacuum freeze-dryer (FZ-6 model manufactured by ALS Co., Ltd.) for $24 \mathrm{~h}$ to produce the freeze-dried product (FD).

2.2.3. Powder X-Ray Diffraction (PXRD). Powder X-ray diffraction was performed using an X-ray diffractometer (MiniFlex II, Rigaku) with Cu radiation, a scan range of $2 \theta=$ $5-40^{\circ}$, and a scan rate of $4^{\circ} / \mathrm{min}$. The intensities of diffraction were measured using a $\mathrm{NaI}$ scintillation counter coupled to a discriminator.

2.2.4. Thermogravimetry/Differential Thermal Analyzer. The thermal behavior of the samples was analyzed using a thermogravimetry/differential thermal analyzer (Thermo plus Evo, Rigaku) under a nitrogen flow rate of $200 \mathrm{~mL} / \mathrm{min}$. The samples were heated at a scanning rate of $5.0^{\circ} \mathrm{C} / \mathrm{min}$ from $30^{\circ} \mathrm{C}$ to $350^{\circ} \mathrm{C}$.

2.2.5. Near Infrared (NIR) Absorption Spectrometry. Each sample was filled in with a Fourier transform type near infrared spectrometer (Buchi N-500: Nippon Buchi), under conditions of a measurement wavelength of 
$10000-4000 \mathrm{~cm}^{-1}$, a measuring time of $8 \mathrm{~s}$, and a measuring temperature of $25^{\circ} \mathrm{C}$ with an interval of $1 \mathrm{~nm}$ of optical path.

\subsection{6. ${ }^{1} \mathrm{H}^{1} \mathrm{H}$ Nuclear Overhauser Effect Spectroscopy (NOESY)} NMR Spectroscopy. Two-dimensional (2D) NOESY NMR spectroscopy and selective 1D-NMR spectroscopy were performed using an NMR spectrometer (Varian NMR System $700 \mathrm{NB}$, Agilent) with a cold probe operating at $699.6 \mathrm{MHz}$ and a $\mathrm{D}_{2} \mathrm{O}$ solution. The measurement conditions were as follows: an acquisition time of $7.0 \mu \mathrm{s}$, a pulse width of $90^{\circ}$, a relaxation delay of $0.267 \mathrm{~s}$, a mixing time of $4.500 \mathrm{~s}$, a fixed delay of $1.500 \mathrm{~s}$, and a temperature of $298 \mathrm{~K}$.

2.2.7. $\alpha$-Glucosidase Activity Inhibition Test. One hundred microliters of each test solution (MT, $\alpha \mathrm{CD}, \gamma \mathrm{CD}, \mathrm{PM}$ $(\mathrm{MT} / \alpha \mathrm{CD}), \mathrm{PM}(\mathrm{MT} / \gamma \mathrm{CD}), \mathrm{FD}(\mathrm{MT} / \alpha \mathrm{CD})$, and $\mathrm{FD}$ $(\mathrm{MT} / \gamma \mathrm{CD})$ ) and $600 \mu \mathrm{L}$ of $0.1 \mathrm{~mol} / \mathrm{L}$ maleate buffer $(\mathrm{pH} 6.0)$ were added to $100 \mu \mathrm{L}$ of a substrate solution (1\% maltose). Thereafter, $200 \mu \mathrm{L}$ of $\alpha$-glucosidase solution (active solution, inactive solution) was added and the solution was incubated for $60 \mathrm{~min}$ at $37^{\circ} \mathrm{C}$ to allow an $\alpha$-glucosidase reaction. The reaction was stopped by heating the solution at $100^{\circ} \mathrm{C}$ for $15 \mathrm{~min}$. Thereafter, $10 \mu \mathrm{L}$ of the reaction solution was dispensed into a 96-well microplate and $200 \mu \mathrm{L}$ of Gluest CII-Test Wako, coloring reagent (Wako Pure Chemical Industries, Ltd.), was added and the solution was incubated for $5 \mathrm{~min}$ at $37^{\circ} \mathrm{C}$. After incubation, the absorbance was measured using a microplate reader (Spectra Max 190 ${ }^{\circledR}$, Molecular Devices Japan Ltd.) at a wavelength of $505 \mathrm{~nm}$. To $2.0 \mathrm{~g}$ of rat acetone powder (intestinal acetone powder from rats, Sigma-Aldrich), $20 \mathrm{~mL}$ of $0.1 \mathrm{~mol} / \mathrm{L}$ maleic acid buffer solution ( $\mathrm{pH}$ 6.0) was added and the mixture was homogenized for $1 \mathrm{~min}$. Thereafter, the mixture was centrifuged and the supernatant was used as an $\alpha$-glucosidase active solution. In addition, this solution was heated at $100^{\circ} \mathrm{C}$ for $15 \mathrm{~min}$ to obtain an inert liquid. The $\alpha$-glucosidase active solution was used as a positive control and the inactive solution was used as a negative control. For the test solution, acarbose was used as the control agent. The $\mathrm{IC}_{50}$ value of acarbose was calculated from the dose-response curves (not given in this paper). The results indicated that the $\mathrm{IC}_{50}$ value of acarbose was $87 \mu \mathrm{g} / \mathrm{mL}$, which was close to the value reported by Yang et al. [7]. Therefore, the concentration of MT was set by taking the ratio between $100 \mathrm{mg}$ of one dose of acarbose and $50 \mathrm{mg}$ of one dose of MT. The concentrations of PM (MT/ $/ \alpha \mathrm{CD}), \mathrm{PM}(\mathrm{MT} / \gamma \mathrm{CD}), \mathrm{FD}(\mathrm{MT} / \alpha \mathrm{CD})$, and FD $(\mathrm{MT} / \gamma \mathrm{CD})$ were adjusted to be equal to that of MT alone. In addition, the concentration of $\alpha \mathrm{CD}$ was adjusted to be equal to that of PM (MT/ $\alpha \mathrm{CD})$ and FD $(\mathrm{MT} / \alpha \mathrm{CD})$, and the concentration of $\gamma \mathrm{CD}$ was equal to that of $\mathrm{PM}(\mathrm{MT} / \gamma \mathrm{CD})$ and $\mathrm{FD}(\mathrm{MT} / \gamma \mathrm{CD})$.

The $\alpha$-glucosidase activity inhibition rate was calculated using the following formula:

$$
\alpha \text {-glucosidase inhibition } \%=100-\frac{(C-D)}{(A-B)} \times 100 \text {, }
$$

where $A$ is the glucose concentration in the positive control, $B$ is the glucose concentration in the negative control, $C$ is the glucose concentration obtained by adding the test solution to the positive control, and $D$ is the glucose concentration obtained by adding the test solution to the negative control.

2.2.8. $\alpha$-Amylase Activity Inhibition Test. Fifty microliters of each test solution (MT, $\alpha \mathrm{CD}, \gamma \mathrm{CD}, \mathrm{PM}(\mathrm{MT} / \alpha \mathrm{CD}), \mathrm{PM}$ $(\mathrm{MT} / \gamma \mathrm{CD}), \mathrm{FD}(\mathrm{MT} / \alpha \mathrm{CD})$, and FD (MT/ $\gamma \mathrm{CD}))$ and $400 \mu \mathrm{L}$ of phosphate buffered saline (pH 7.4) were added to $450 \mu \mathrm{L}$ of a substrate solution ( $0.5 \%$ starch aqueous solution). Thereafter, $100 \mu \mathrm{L}$ of $\alpha$-amylase solution (active solution, inactive solution) was added and the mixture was incubated for $20 \mathrm{~min}$ at $37^{\circ} \mathrm{C}$ to perform an $\alpha$-amylase reaction. Thereafter, $500 \mu \mathrm{L}$ of DSN reagent (1\% 3,5-dinitrosalicylic acid and $12 \%$ potassium sodium tartrate in $0.4 \mathrm{~mol} / \mathrm{L} \mathrm{NaOH}$ ) was added to the incubated solution and the mixture was heated at $100^{\circ} \mathrm{C}$ for $15 \mathrm{~min}$ to stop the reaction. The reaction solution $(200 \mu \mathrm{L})$ was then dispensed into a 96-well microplate and the absorbance was ELISA-assayed at a wavelength of $540 \mathrm{~nm}$ using a microplate reader (Spectra Max 190, Molecular Devices Japan KK). To $16.5 \mathrm{mg}$ of porcine pancreatic-derived $\alpha$-amylase ( $\alpha$-amylase from porcine pancreas, 19.5 unite amylase/mg, SIGMA), $100 \mathrm{~mL}$ of phosphate buffered saline was added. After ultrasonic treatment for $10 \mathrm{~min}$, the mixture was centrifuged and the supernatant was used as an $\alpha$ amylase active solution. In addition, this solution was heated at $100^{\circ} \mathrm{C}$ for $15 \mathrm{~min}$ to obtain an inert liquid. The $\alpha$-amylase active solution was used as a positive control and the inactive solution as a negative control. For the test solution, acarbose was used as a control agent. The $\mathrm{IC}_{50}$ value of acarbose was calculated from the dose-response curves (not given in this paper). The results indicated that the $\mathrm{IC}_{50}$ value of acarbose was $20 \mu \mathrm{g} / \mathrm{mL}$, which was close to the value reported by Wickramaratne et al. [8]. Therefore, the concentration of MT was set by taking the ratio between $100 \mathrm{mg}$ of one dose of acarbose and $50 \mathrm{mg}$ of one dose of MT. The concentrations of PM $(\mathrm{MT} / \alpha \mathrm{CD}), \mathrm{PM}(\mathrm{MT} / \gamma \mathrm{CD}), \mathrm{FD}(\mathrm{MT} / \alpha \mathrm{CD})$, and FD $(\mathrm{MT} / \gamma \mathrm{CD})$ were adjusted to be equal to that of MT alone. In addition, the concentration of $\alpha \mathrm{CD}$ was adjusted to be equal to that of PM $(\mathrm{MT} / \alpha \mathrm{CD})$ and $\mathrm{FD}(\mathrm{MT} / \alpha \mathrm{CD})$, and the concentration of $\gamma \mathrm{CD}$ was adjusted to be equal to that of $\mathrm{PM}$ $(\mathrm{MT} / \gamma \mathrm{CD})$ and $\mathrm{FD}(\mathrm{MT} / \gamma \mathrm{CD})$.

The $\alpha$-amylase activity inhibition rate was calculated using the following formula:

$$
\alpha \text {-Amylase Inhibition } \%=100-\frac{(C-D)}{(A-B)} \times 100,
$$

where $A$ is the glucose concentration in the positive control, $B$ is the glucose concentration in the negative control, $C$ is the glucose concentration obtained by adding the test solution to the positive control, and $D$ is the glucose concentration obtained by adding the test solution to the negative control.

\section{Results and Discussion}

3.1. PXRD Measurement. PXRD was performed to examine the crystalline state of MT and CDs in the FD $(\mathrm{MT} / \alpha \mathrm{CD})$ and $\mathrm{FD}(\mathrm{MT} / \gamma \mathrm{CD})$ preparations (Figure 2). Intact MT exhibited characteristic diffraction peaks at $2 \theta=15.5^{\circ}$ and $19.2^{\circ}$. 


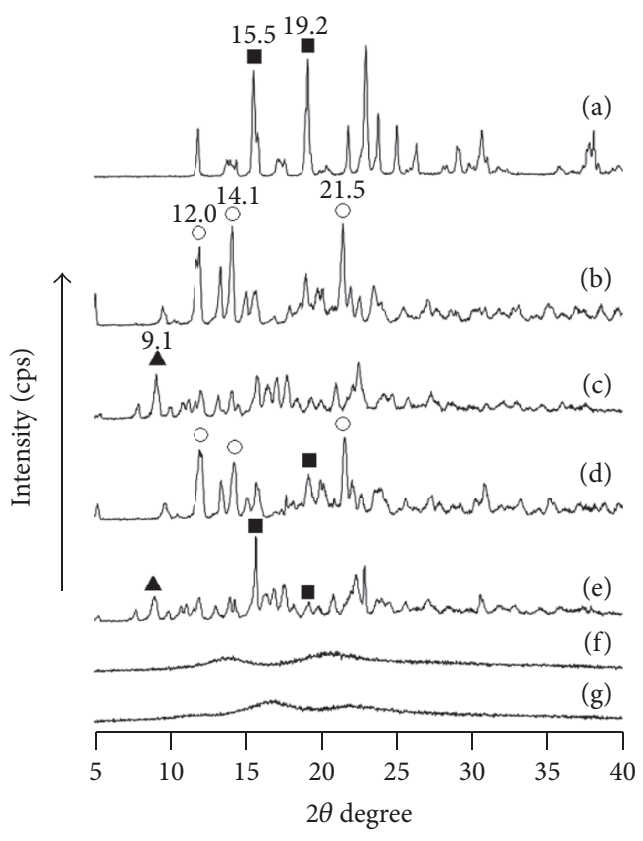

FIGURE 2: PXRD patterns of MT $/ \alpha \mathrm{CD}$ and MT $/ \gamma \mathrm{CD}$ systems. (a) MT intact, (b) $\alpha \mathrm{CD}$, (c) $\gamma \mathrm{CD}$, (d) PM (MT/ $\alpha \mathrm{CD}=1 / 1$ ), (e) $\mathrm{PM}$ (MT/ $\gamma \mathrm{CD}=1 / 1)$, (f) FD (MT/ $\alpha \mathrm{CD}=1 / 1),(\mathrm{g}) \mathrm{FD}(\mathrm{MT} / \gamma \mathrm{CD}=1 / 1)$.

๓: MT original, $\mathrm{O}: \alpha \mathrm{CD}$ original, $\mathbf{\Delta}: \gamma \mathrm{CD}$ original.

$\alpha \mathrm{CD}$ exhibited characteristic diffraction peaks at $2 \theta=12.0^{\circ}$, $14.1^{\circ}, 21.52^{\circ}$. The PM $(\mathrm{MT} / \alpha \mathrm{CD})$ exhibited diffraction peaks derived from $\alpha \mathrm{CD}$ at $2 \theta=12.0^{\circ}, 14.1^{\circ}, 21.5^{\circ}$ and MT at $2 \theta$ $=19.2^{\circ}$. However, FD $(\mathrm{MT} / \alpha \mathrm{CD})$ exhibited a halo pattern. $\gamma \mathrm{CD}$ exhibited a characteristic diffraction peak at $2 \theta=9.1^{\circ}$. The PM $(\mathrm{MT} / \gamma \mathrm{CD})$ exhibited diffraction peaks derived from $\gamma \mathrm{CD}$ at $2 \theta=9.10^{\circ}$ and $\mathrm{MT}$ at $2 \theta=15.5^{\circ}$ and $19.16^{\circ}$. However, FD $(\mathrm{MT} / \gamma \mathrm{CD})$ exhibited a halo pattern similar to that of $\mathrm{FD}(\mathrm{MT} / \alpha \mathrm{CD})$ and an amorphous state was observed. An amorphous state observed during the PXRD measurement of a solid dispersion of $\mathrm{CD}$ and a guest molecule suggests that there is a possibility that $\mathrm{CD}$ and the guest molecule formed an inclusion complex $[9,10]$. From this fact, we presumed that some interaction occurred in the crystalline state during the freeze-drying preparation of FD (MT/ $\alpha \mathrm{CD})$ and $\mathrm{FD}(\mathrm{MT} / \gamma \mathrm{CD})$.

3.2. TG-DTA. An amorphous state was observed in FD $(\mathrm{MT} / \alpha \mathrm{CD})$ and $\mathrm{FD}(\mathrm{MT} / \gamma \mathrm{CD})$ during the PXRD measurement. Therefore, a TG-DTA measurement was performed to confirm the thermal behavior (Figures 3 and 4). For the intact MT, thermal weight reduction was observed around $227^{\circ} \mathrm{C}$. Conversely, a thermal weight decrease was observed at $252^{\circ} \mathrm{C}$ and $246^{\circ} \mathrm{C}$ for FD (MT/ $\left.\alpha \mathrm{CD}\right)$ and $\mathrm{FD}(\mathrm{MT} / \gamma \mathrm{CD})$. In addition, in the intact MT, an endothermic peak owing to the melting point of MT was confirmed around $142^{\circ} \mathrm{C}$. Even in the PM (MT/ $\alpha \mathrm{CD})$ and PM $(\mathrm{MT} / \gamma \mathrm{CD})$, an endothermic peak owing to the melting point of MT was observed around $141^{\circ} \mathrm{C}$. However, an endothermic peak owing to the melting point of MT was not observed in FD (MT/ $\alpha \mathrm{CD})$ and FD (MT/ $/ \mathrm{CD})$. The increase in the thermal weight reduction temperature

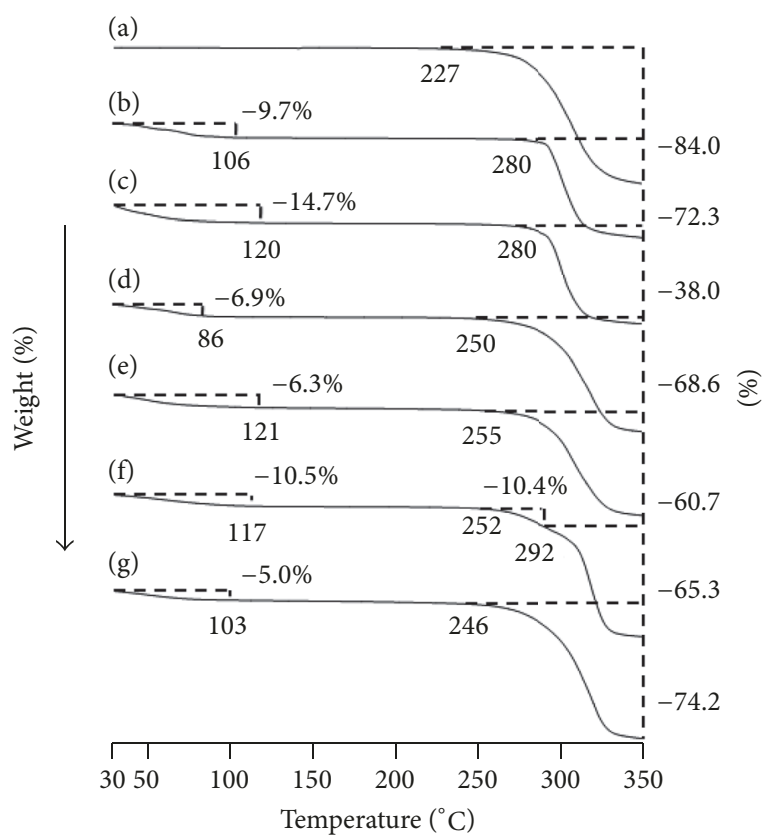

Figure 3: TG curves of MT/ $\alpha \mathrm{CD}$ and MT/ $\gamma \mathrm{CD}$ systems. (a) MT, (b) $\alpha \mathrm{CD},(\mathrm{c}) \gamma \mathrm{CD},(\mathrm{d}) \mathrm{PM}(\mathrm{MT} / \alpha \mathrm{CD}=1 / 1),(\mathrm{e}) \mathrm{PM}(\mathrm{MT} / \gamma \mathrm{CD}=1 / 1),(\mathrm{f})$ $\mathrm{FD}(\mathrm{MT} / \alpha \mathrm{CD}=1 / 1),(\mathrm{g}) \mathrm{FD}(\mathrm{MT} / \gamma \mathrm{CD}=1 / 1)$.

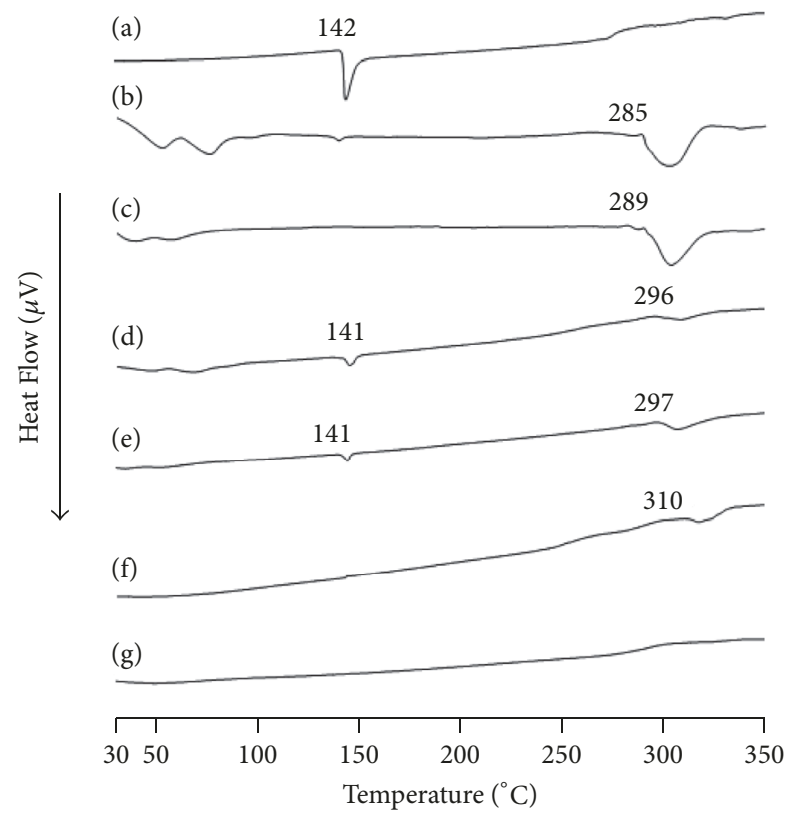

FIGURE 4: DTA curves of MT/ $\alpha \mathrm{CD}$ and MT $/ \gamma \mathrm{CD}$ systems. (a) MT, (b) $\alpha \mathrm{CD},(\mathrm{c}) \gamma \mathrm{CD}$, (d) PM $(\mathrm{MT} / \alpha \mathrm{CD}=1 / 1)$, (e) $\mathrm{PM}(\mathrm{MT} / \gamma \mathrm{CD}=1 / 1)$, (f) $\mathrm{FD}(\mathrm{MT} / \alpha \mathrm{CD}=1 / 1)$, (g) FD $(\mathrm{MT} / \gamma \mathrm{CD}=1 / 1)$.

and the disappearance of the endothermic peak of the guest molecule indicated that an inclusion complex made of CD and the guest molecule was formed [11, 12]. These changes in thermal behavior suggested intermolecular interactions in $\mathrm{MT} / \alpha \mathrm{CD}$ and $\mathrm{MT} / \gamma \mathrm{CD}$ lyophilizates. Incidentally, there was no change in the results of PXRD and TG-DTA measurement after a month of preparation of FD $(\mathrm{MT} / \alpha \mathrm{CD})$ and $\mathrm{FD}$ 


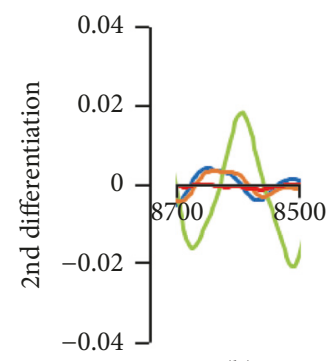

(b)

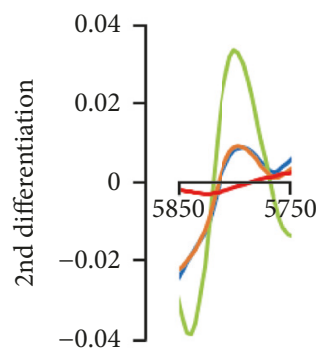

(c)

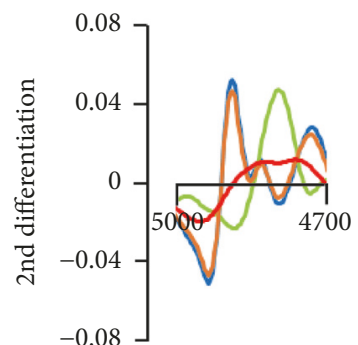

(d)

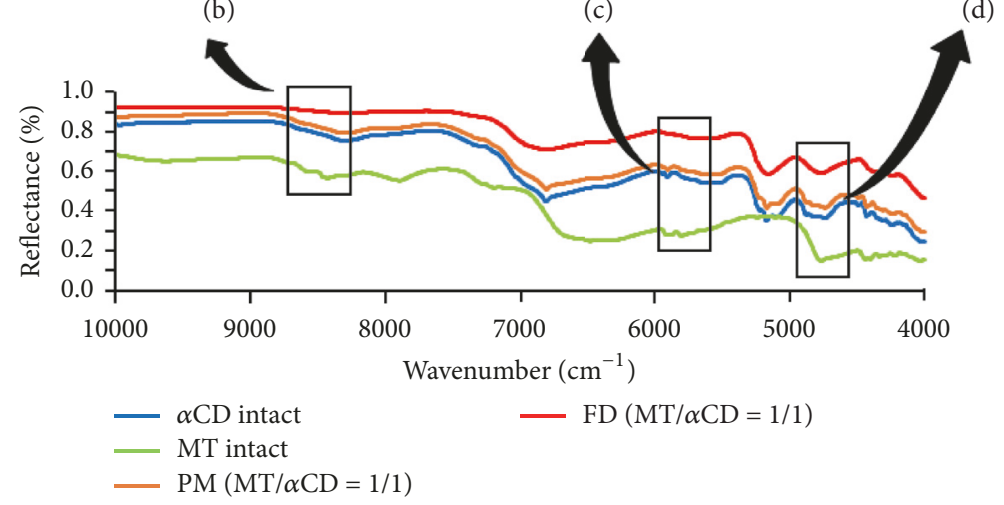

(a)

FIGURE 5: NIR absorption spectra of MT/ $\alpha \mathrm{CD}$ systems and second-differentiation NIR absorption spectra of MT/ $\alpha \mathrm{CD}$ systems ((b) alkyl group, (c) alkyl group, and (d) hydroxy group).

$(\mathrm{MT} / \gamma \mathrm{CD})$ (not shown data). Therefore, the freeze-dried product $(\mathrm{MT} / \alpha \mathrm{CD}$ and $\mathrm{MT} / \gamma \mathrm{CD})$ presume is stable.

3.3. NIR. PXRD measurement and TG-DTA measurement suggested inclusion complex formation in FD $(\mathrm{MT} / \alpha \mathrm{CD})$ and $\mathrm{FD}(\mathrm{MT} / \gamma \mathrm{CD})$. Therefore, to verify the detailed intermolecular interaction, the NIR absorption spectrum was measured (Figures 5 and 6).

The results of the NIR measurement indicated that the $-\mathrm{OH}$ group was observed around $4800 \mathrm{~cm}^{-1}$ [13] and $6660 \mathrm{~cm}^{-1}-7140 \mathrm{~cm}^{-1}$ [14]. In addition, the $-\mathrm{CH}_{2}$ group was observed around $5800 \mathrm{~cm}^{-1}$ [15] and $8145 \mathrm{~cm}^{-1}-9153 \mathrm{~cm}^{-1}$ [16]. From the results of the NIR measurement, a peak derived from an -OH group appeared around $4800 \mathrm{~cm}^{-1}$ and that from a $-\mathrm{CH}_{2}$ group appeared around $5800 \mathrm{~cm}^{-1}$ and $8600 \mathrm{~cm}^{-1}$ for MT. In $\alpha \mathrm{CD}$ alone, a peak derived from an $\mathrm{OH}$ group appeared around $4900 \mathrm{~cm}^{-1}$ (Figure 5(a)). In the second derivative spectrum, the peak of the $-\mathrm{CH}_{2}$ group around $8600 \mathrm{~cm}^{-1}$ (Figure 5(b)) and $5800 \mathrm{~cm}^{-1}$ (Figure 5(c)) of MT was broadened in FD $(\mathrm{MT} / \alpha \mathrm{CD})$. In addition, the peak derived from the $-\mathrm{OH}$ group around $4800 \mathrm{~cm}^{-1}$ of MT and the $-\mathrm{OH}$ group around $4900 \mathrm{~cm}^{-1}$ of $\alpha \mathrm{CD}$ was broadened (Figure 5(d)). A broadened or shifted peak in the NIR measurement indicated that there were intermolecular interactions between the drug and functional group [17]. This suggested that there were intermolecular interactions between the $-\mathrm{CH}_{2}$ group and $-\mathrm{OH}$ group of $\mathrm{MT}$ and the $-\mathrm{OH}$ group of $\alpha \mathrm{CD}$ in FD (MT/ $\alpha \mathrm{CD})$.

In addition, in $\gamma \mathrm{CD}$ alone, a peak derived from the -OH group appeared around $7000 \mathrm{~cm}^{-1}$ (Figure 6(a)). In the results of the second derivative spectrum, the peak of the
-OH group around $4800 \mathrm{~cm}^{-1}$ (Figure 6(e)) and the peak of $-\mathrm{CH}_{2}$ group around $8600 \mathrm{~cm}^{-1}$ (Figure $\left.6(\mathrm{~b})\right)$ and $5800 \mathrm{~cm}^{-1}$ (Figure 5(d)) for MT were broadened in FD (MT/ $\gamma \mathrm{CD})$.

In addition, the peak derived from the $-\mathrm{OH}$ group around $7000 \mathrm{~cm}^{-1}$ of $\gamma \mathrm{CD}$ shifted to the higher wave number (Figure 6(c)). This suggested that there were intermolecular interactions between the $-\mathrm{CH}_{2}$ group and the $-\mathrm{OH}$ group in $\mathrm{MT}$ and the $-\mathrm{OH}$ group in $\gamma \mathrm{CD}$ in FD $(\mathrm{MT} / \gamma \mathrm{CD})$.

Miglitol has a $-\mathrm{CH}_{2}$ group at the 6 th position in its side chain and at a cyclic structure. Therefore, in the NIR measurement, it is impossible to determine whether the $-\mathrm{CH}_{2}$ group is of the cyclic structure or the 6th position in the side chain. Therefore, detailed examination by 2D-NMR measurement is necessary.

3.4. ${ }^{1} \mathrm{H}^{-}{ }^{1} \mathrm{H}$ NOESY NMR Spectroscopy. NIR measurement indicated an intermolecular interaction between the $-\mathrm{CH}_{2}$ and $-\mathrm{OH}$ group of $\mathrm{MT}$ and the $-\mathrm{OH}$ group of $\alpha \mathrm{CD}$ and between the $-\mathrm{CH}_{2}$ and $-\mathrm{OH}$ group of $\mathrm{MT}$ and the $-\mathrm{OH}$ group of $\gamma \mathrm{CD}$. Therefore, the detailed intermolecular interaction was further evaluated. First, ${ }^{1} \mathrm{H}-\mathrm{NMR}$ measurement of MT alone was conducted to confirm the attributions of MT. The results indicated that the $-\mathrm{CH}(\mathrm{h})$ of $\mathrm{MT}$ exhibited two peaks at $3.62 \mathrm{ppm}\left(\mathrm{h}_{1}\right)$ and $3.72 \mathrm{ppm}\left(\mathrm{h}_{2}\right)$ (Figure 7$)$. Thereafter, ${ }^{1} \mathrm{H}$ ${ }^{1} \mathrm{H}$ NOESY NMR spectroscopy measurement was performed (Figures 8 and 9). In FD (MT/ $\alpha \mathrm{CD})$, cross peaks were observed between the peak for the $-\mathrm{CH}\left(\mathrm{h}_{2}: 3.72 \mathrm{ppm}\right)$ in $\mathrm{MT}$ and the H-3 (3.76 ppm) protons in $\alpha \mathrm{CD}$ (Figure 8). In general, it has been reported that by observing $\mathrm{H}-3,5$, and 6 protons of the $\mathrm{CD}$ cavity and protons of the guest molecule using ${ }^{1} \mathrm{H}-{ }^{1} \mathrm{H}-\mathrm{NMR}$, the structure of the inclusion complex 


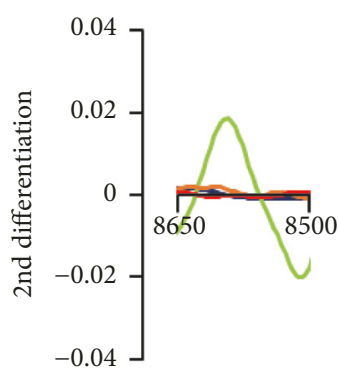

(b)

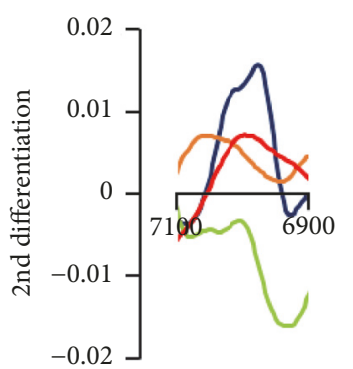

(c)

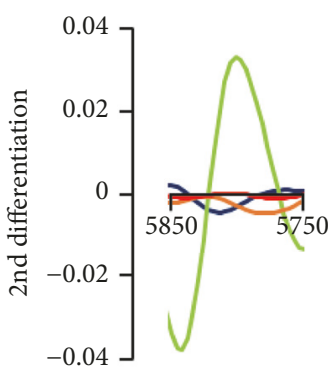

(d)

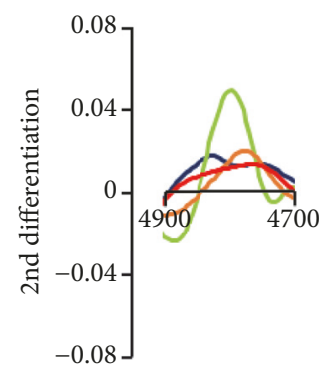

(e)

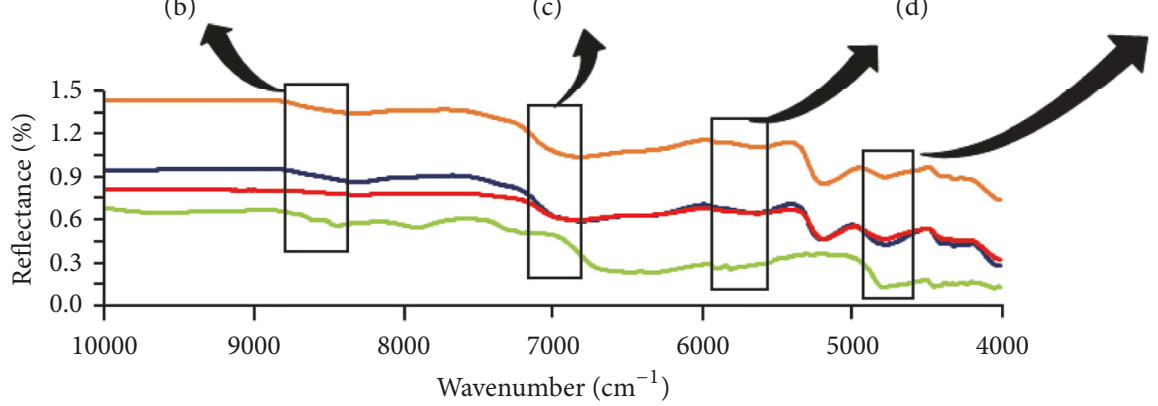

$\gamma \mathrm{CD}$ intact
MT intact
PM $(\mathrm{MT} / \alpha \mathrm{CD}=1 / 1)$

$-\mathrm{FD}(\mathrm{MT} / \alpha \mathrm{CD}=1 / 1)$

(a)

FIGURE 6: NIR absorption spectra of MT/ $\gamma$ CD systems and second-differentiation NIR absorption spectra of MT/ $\gamma$ CD systems ((b) alkyl group of MT, (c) hydroxy group of $\gamma \mathrm{CD}$, (d) alkyl group of MT, and (e) hydroxy group of MT).<smiles>OCCN1C[C@H](O)[C@@H](O)[C@H](O)[C@H]1CO</smiles>

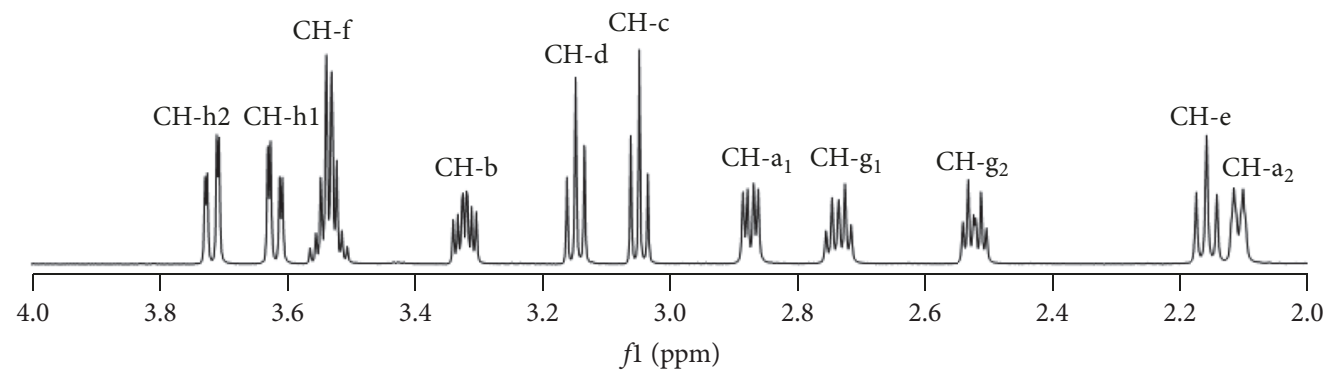

FIgURE 7: Proton-NOESY NMR spectra of MT in $\mathrm{D}_{2} \mathrm{O}$.

can be elucidated [18]. In addition, from this result, a cross peak between $\mathrm{H}-3$ showing the wide edge of $\mathrm{CD}$ and the - $\mathrm{CH}$ $\left(\mathrm{h}_{2}: 3.72 \mathrm{ppm}\right)$ in MT was observed in FD $(\mathrm{MT} / \alpha \mathrm{CD})$. This suggested that the inclusion complex made of $\alpha \mathrm{CD}$ and MT was in a form covering the alkyl group of MT from the cavity of a wide edge of $\mathrm{CD}$ with respect to the alkyl group of the - $\mathrm{CH}$ (h) of MT.
Additionally, in $\mathrm{FD}(\mathrm{MT} / \gamma \mathrm{CD})$, cross peaks were observed between the peak for $-\mathrm{CH}\left(\mathrm{h}_{1}: 3.62 \mathrm{ppm}, \mathrm{h}_{2}\right.$ : $3.72 \mathrm{ppm}$ ) of MT and the H-3 (3.72 ppm) and H-6 (3.65 ppm) protons of $\gamma \mathrm{CD}$ (Figure 9). From this result, a cross peak between $\mathrm{H}-3$ showing the wide edge of $\mathrm{CD}$ and $-\mathrm{CH}\left(\mathrm{h}_{2}\right.$ : $3.72 \mathrm{ppm})$ of MT was observed in FD $(\mathrm{MT} / \gamma \mathrm{CD})$. This suggested that the inclusion complex made of $\gamma \mathrm{CD}$ and MT 


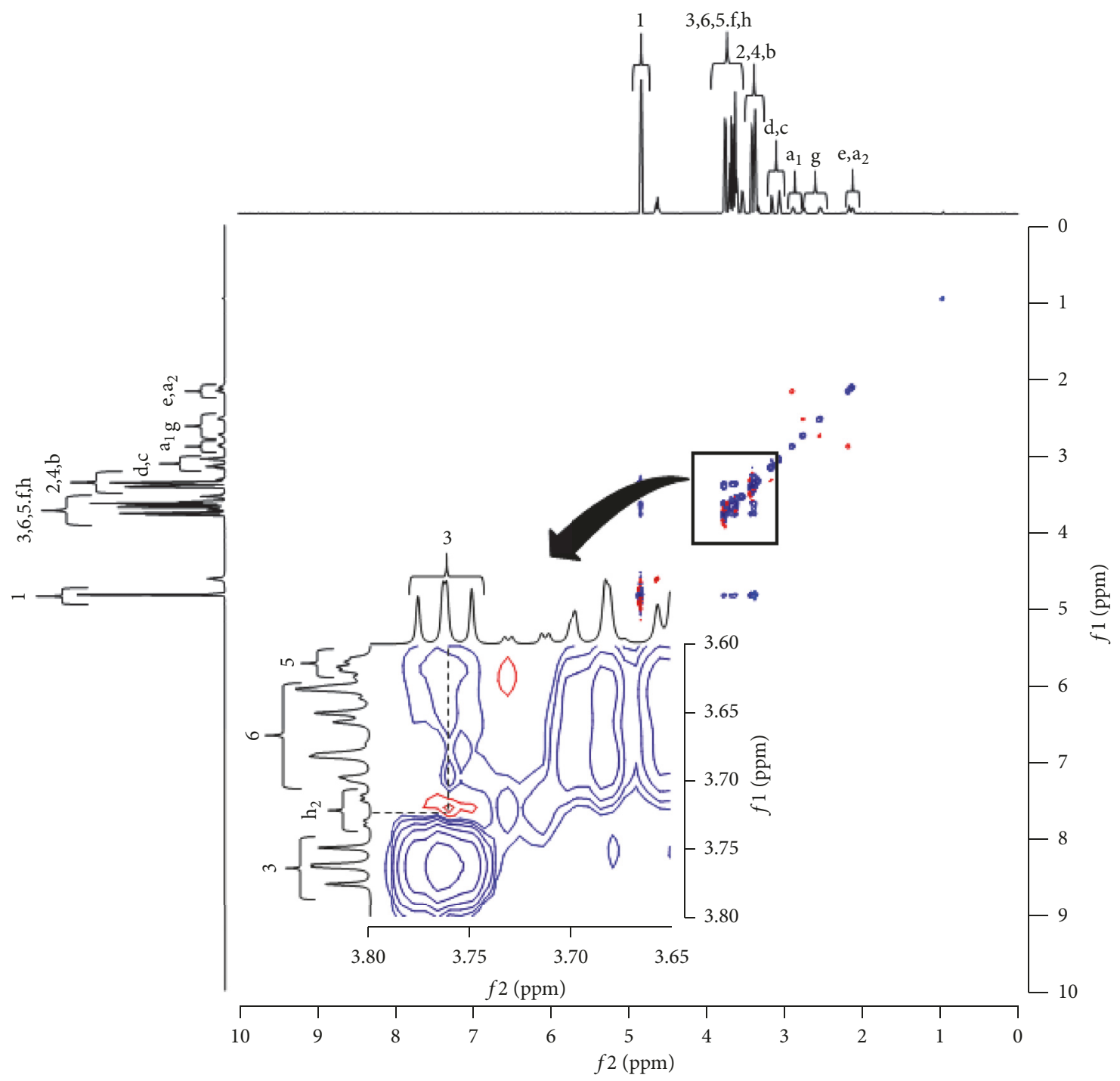

FIGURE $8:{ }^{1} \mathrm{H}^{-1} \mathrm{H}$-NOESY NMR spectra of MT/ $\alpha \mathrm{CD}$ system.

included a form covering the alkyl group of MT from the cavity of a wide edge of $\mathrm{CD}$ with respect to the alkyl group of the $-\mathrm{CH}(\mathrm{h})$ in MT. This confirmed that the inclusion complex with MT was similar between that with $\alpha \mathrm{CD}$ and that with $\gamma \mathrm{CD}$ with different cavity diameters.

3.5. $\alpha$-Glucosidase Activity Inhibition Test. Inclusion complex formation was confirmed for FD $(\mathrm{MT} / \alpha \mathrm{CD})$ and $\mathrm{FD}$ $(\mathrm{MT} / \gamma \mathrm{CD})$. Because deterioration of bioactivity is an area of concern for inclusion preparations, the MT in inclusion complexes was tested for $\alpha$-glucosidase activity (Table 1). For intact MT, a $51.2 \%$ inhibition of $\alpha$-glucosidase activity was observed. In addition, FD (MT/ $\alpha \mathrm{CD})$ and FD (MT/ $/ \mathrm{CD})$ exhibited inhibition rates of $56.2 \%$ and $56.6 \%$, respectively, which was similar to the inhibition rates observed with intact MT. Inhibition of $\alpha$-glucosidase activity was not observed in $\alpha \mathrm{CD}$ or $\gamma \mathrm{CD}$. This indicated that the $\alpha$-glucosidase inhibitory activity depended on the concentration of MT and confirmed
TABLE 1: Inhibitory activities $\alpha$-glucosidase and $\alpha$-amylase.

\begin{tabular}{lcc}
\hline & \multicolumn{2}{c}{ Percentage of inhibition } \\
& $\alpha$-Glucosidase & $\alpha$-Amylase \\
\hline MT & $51.2 \pm 7.3$ & - \\
$\alpha \mathrm{CD}$ & - & $4.4 \pm 2.5$ \\
$\gamma \mathrm{CD}$ & - & $3.1 \pm 1.1$ \\
$\mathrm{PM}(\mathrm{MT} / \alpha \mathrm{CD})$ & $51.5 \pm 10.2$ & $0.1 \pm 0.8$ \\
$\mathrm{PM}(\mathrm{MT} / \gamma \mathrm{CD})$ & $56.2 \pm 6.8$ & $3.2 \pm 2.2$ \\
$\mathrm{FD}(\mathrm{MT} / \alpha \mathrm{CD})$ & $49.9 \pm 7.4$ & $2.8 \pm 1.1$ \\
$\mathrm{FD}(\mathrm{MT} / \gamma \mathrm{CD})$ & $56.6 \pm 4.9$ & $1.3 \pm 2.6$ \\
\hline
\end{tabular}

Values are expressed as mean \pm standard deviation $(n=3)$. Each data value showed statistically significant difference at $p$ value $<0.05$ using Turkey's multiple comparison tests.

that the $\alpha$-glucosidase inhibitory activity of MT in the inclusion complex was sufficiently maintained. 


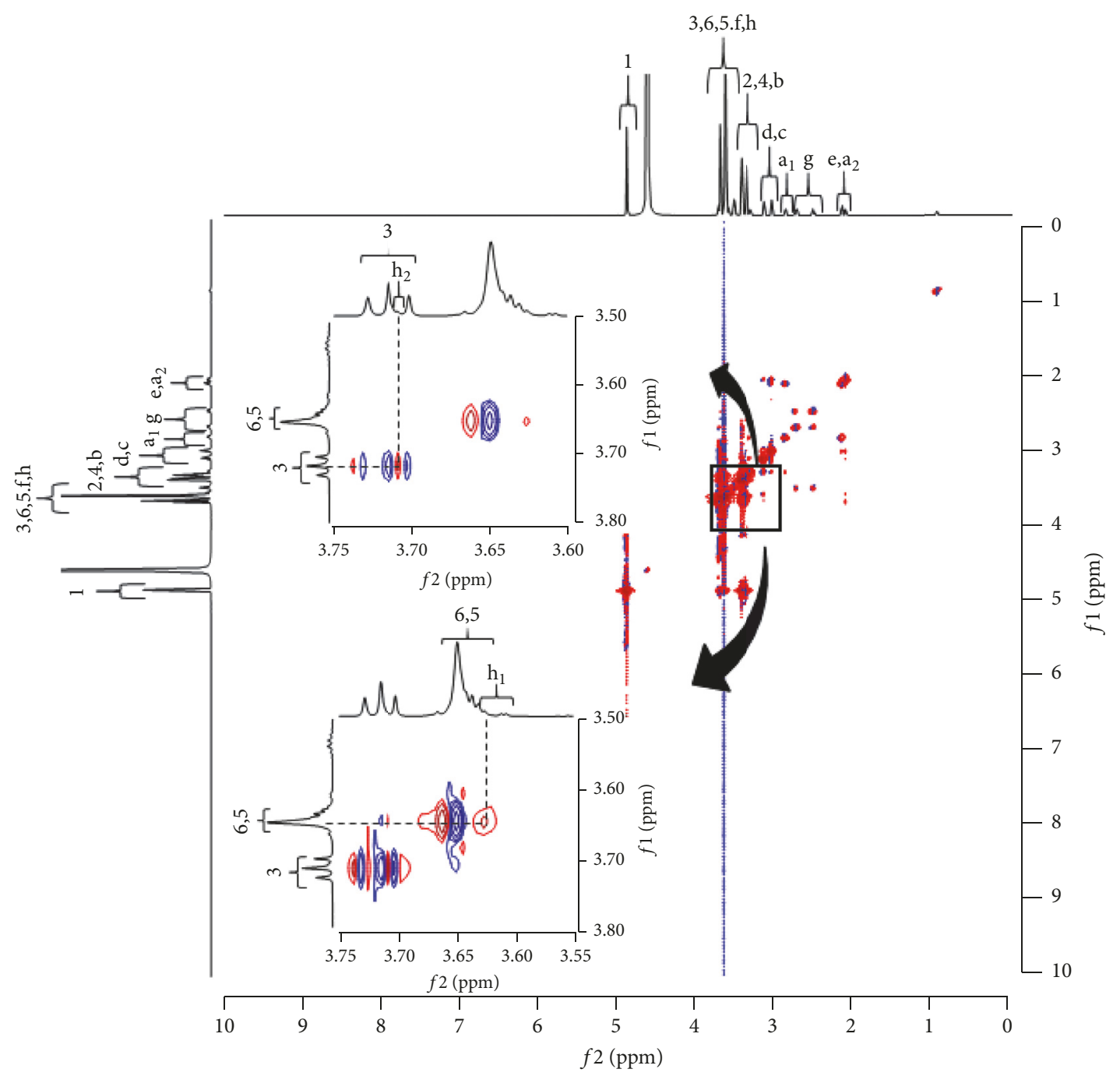

FIgURE 9: ${ }^{1} \mathrm{H}^{-1} \mathrm{H}$-NOESY NMR spectra of MT/ $\gamma \mathrm{CD}$ system.

3.6. $\alpha$-Amylase Activity Inhibition Test. $\alpha \mathrm{CD}$ has been reported to inhibit $\alpha$-amylase activity. To confirm the influence on the inhibition of $\alpha$-amylase activity by the formation of these complexes, an $\alpha$-amylase activity inhibition test was conducted (Table 1). Intact MT did not inhibit $\alpha$-amylase activity. Conversely, $\alpha \mathrm{CD}$ and $\gamma \mathrm{CD}$ exhibited inhibition rates of $4.41 \%$ and $3.10 \%$. In addition, FD (MT/ $\alpha \mathrm{CD})$ and $\mathrm{FD}$ $(\mathrm{MT} / \gamma \mathrm{CD})$ exhibited inhibition rates of $3.21 \%$ and $1.29 \%$, which were almost equal to the inhibition rates observed with $\alpha \mathrm{CD}$ and $\gamma \mathrm{CD}$ alone. This was due to inhibition of $\alpha$-amylase activity by both $\alpha \mathrm{CD}$ and $\gamma \mathrm{CD}$ and indicated that the $\alpha$ amylase inhibitory activity of $\alpha \mathrm{CD}$ and $\gamma \mathrm{CD}$ in the prepared complex was sufficiently maintained. The dose of CD used to prepare the FD was very small compared with the dose reported to affect the inhibition of $\alpha$-amylase activity [19]. Therefore, the $\alpha$-amylase activity rate was very low. In the future, it will be necessary to confirm these results under different conditions. Further investigation should evaluate the effects on blood sugar in animal studies using these preparations.
In this study, $\mathrm{MT} / \alpha \mathrm{CD}$ and $\mathrm{MT} / \gamma \mathrm{CD}$ were evaluated, but a preparation containing MT/ $\beta \mathrm{CD}$ should also be evaluated. However, MT/ $\beta \mathrm{CD}$ is not as easily prepared by freeze-drying as $\mathrm{MT} / \alpha \mathrm{CD}$ and $\mathrm{MT} / \gamma \mathrm{CD}$. The cavity of $\beta \mathrm{CD}$ is hydrophobic compared to $\alpha \mathrm{CD}$ and $\gamma \mathrm{CD}$. On the other hand, MT of a drug used as a guest molecule in this study is a watersoluble drug. Therefore, MT/ $\beta \mathrm{CD}$ inclusion complex might not be confirmed. In the future, we plan to develop a better preparation method.

\section{Conclusion}

In this study, we prepared MT/ $\alpha \mathrm{CD}$ complex and MT $/ \gamma \mathrm{CD}$ complex using a freeze-drying method. In addition, it was confirmed that the structure of the inclusion complex differed depending on the size of the CD ring. Furthermore, we found that there was no influence on the inhibition of $\alpha$-glucosidase or $\alpha$-amylase activity depending on the preparation process used for the FD. 


\section{Disclosure}

The authors alone are responsible for the content and writing of this paper.

\section{Conflicts of Interest}

The authors declare that there are no conflicts of interest regarding the publication of this paper.

\section{Acknowledgments}

The authors are grateful to the Cyclo Chem Co., Ltd. (for providing $\alpha \mathrm{CD}$ and $\gamma \mathrm{CD}$ ), SANWA KAGAKU KENKYUSHO Co., Ltd. (for providing Miglitol), and Dr. Toshiyasu Tarumi at Buchi Labortechnik AG (for providing support for NIR spectroscopy).

\section{References}

[1] E. S. Ford, M. M. Bergmann, H. Boeing, C. Li, and S. Capewell, "Healthy lifestyle behaviors and all-cause mortality among adults in the United States," Preventive Medicine, vol. 55, no. 1, pp. 23-27, 2012.

[2] R. Koukiekolo, V. Desseaux, Y. Moreau, G. Marchis-Mouren, and M. Santimone, "Mechanism of porcine pancreatic $\alpha$ amylase: inhibition of amylose and maltopentaose hydrolysis by $\alpha$-, $\beta$ - and $\gamma$-cyclodextrins," European Journal of Biochemistry, vol. 268, no. 3, pp. 841-848, 2001.

[3] M. Sugahara, Y. Inoue, I. Murata et al., "Effect of cyclodextrin on postprandial blood glucose and triglycerides," International Journal Pharmacy, vol. 6, no. 3, pp. 13-19, 2016.

[4] A. H. Alomrani, G. A. Shazly, A. A. A. F. Amara, and M. M. Badran, "Itraconazole-hydroxypropyl- $\beta$-cyclodextrin loaded deformable liposomes: in vitro skin penetration studies and antifungal efficacy using Candida albicans as model," Colloids and Surfaces B: Biointerfaces, vol. 121, pp. 74-81, 2014.

[5] Y. Inoue, N. Sekiya, K. Katayama et al., "Stabilizing effect of $\beta$-cyclodextrin on Limaprost, a PGE1 derivative, in Limaprost alfadex tablets (Opalmon ${ }^{\circledR}$ ) in highly humid conditions," Chemical \& Pharmaceutical Bulletin, vol. 62, no. 8, pp. 786-792, 2014.

[6] J. Szejtli and L. Szente, "Elimination of bitter, disgusting tastes of drugs and foods by cyclodextrins," European Journal of Pharmaceutics and Biopharmaceutics, vol. 61, no. 3, pp. 115-125, 2005.

[7] J.-Y. Yang, J.-H. Park, N. Chung, and H.-S. Lee, "Inhibitory potential of constituents from Osmanthus fragrans and structural analogues against advanced glycation end products, $\alpha$ amylase, $\alpha$-glucosidase, and oxidative stress," Scientific Reports, vol. 7, Article ID 45746, 2017.

[8] M. N. Wickramaratne, J. C. Punchihewa, and D. B. M. Wickramaratne, "In-vitro alpha amylase inhibitory activity of the leaf extracts of adenanthera pavonina," BMC Complementary and Alternative Medicine, vol. 16, no. 1, Article ID 466, 2016.

[9] R. O. Williams III, V. Mahaguna, and M. Sriwongjanya, "Characterization of an inclusion complex of cholesterol and hydroxypropyl- $\beta$-cyclodextrin," European Journal of Pharmaceutics and Biopharmaceutics, vol. 46, no. 3, pp. 355-360, 1998.

[10] T. Pralhad and K. Rajendrakumar, "Study of freeze-dried quercetin-cyclodextrin binary systems by DSC, FT-IR, X-ray diffraction and SEM analysis," Journal of Pharmaceutical and Biomedical Analysis, vol. 34, no. 2, pp. 333-339, 2004.

[11] L. P. Fernandes, Z. Éhen, T. F. Moura, C. Novák, and J. Sztatisz, "Characterization of Lippia sidoides oil extract-b-cyclodextrin complexes using combined thermoanalytical techniques," Journal of Thermal Analysis and Calorimetry, vol. 78, no. 2, pp. 557573, 2004.

[12] P. Guo, Y. Su, Q. Cheng, Q. Pan, and H. Li, "Crystal structure determination of the $\beta$-cyclodextrin-p-aminobenzoic acid inclusion complex from powder X-ray diffraction data," Carbohydrate Research, vol. 346, no. 7, pp. 986-990, 2011.

[13] R. G. Dambergs, A. Kambouris, L. Francis, and M. Gishen, "Rapid analysis of methanol in grape-derived distillation products using near-infrared transmission spectroscopy," Journal of Agricultural and Food Chemistry, vol. 50, no. 11, pp. 3079-3084, 2002.

[14] T. A. Lestander, M. Rudolfsson, L. Pommer, and A. Nordin, "NIR provides excellent predictions of properties of biocoal from torrefaction and pyrolysis of biomass," Green Chemistry, vol. 16, no. 12, pp. 4906-4913, 2014.

[15] A. D. Zotte, P. Berzaghi, L.-M. Jansson, and I. Andrighetto, “The use of near-infrared reflectance spectroscopy (NIRS) in the prediction of chemical composition of freeze-dried egg yolk and discrimination between different $\mathrm{n}-3$ PUFA feeding sources," Animal Feed Science and Technology, vol. 128, no. 1-2, pp. 108121, 2006.

[16] V. Gaydou, J. Kister, and N. Dupuy, "Evaluation of multiblock NIR/MIR PLS predictive models to detect adulteration of diesel/biodiesel blends by vegetal oil," Chemometrics and Intelligent Laboratory Systems, vol. 106, no. 2, pp. 190-197, 2011.

[17] S. Duri and C. D. Tran, "Supramolecular composite materials from cellulose, chitosan, and cyclodextrin: facile preparation and their selective inclusion complex formation with endocrine disruptors," Langmuir, vol. 29, no. 16, pp. 5037-5049, 2013.

[18] A. Lis-Cieplak, J. Sitkowski, and W. Kolodziejski, "Comparative proton nuclear magnetic resonance studies of amantadine complexes formed in aqueous solutions with three major cyclodextrins," Journal of Pharmaceutical Sciences, vol. 103, no. 1, pp. 274-282, 2014

[19] N. Oudjeriouat, Y. Moreau, M. Santimone, B. Svensson, G. Marchis-Mouren, and V. Desseaux, "On the mechanism of $\alpha$-amylase. Acarbose and cyclodextrin inhibition of barley amylase isozymes," European Journal of Biochemistry, vol. 270, no. 19, pp. 3871-3879, 2003. 

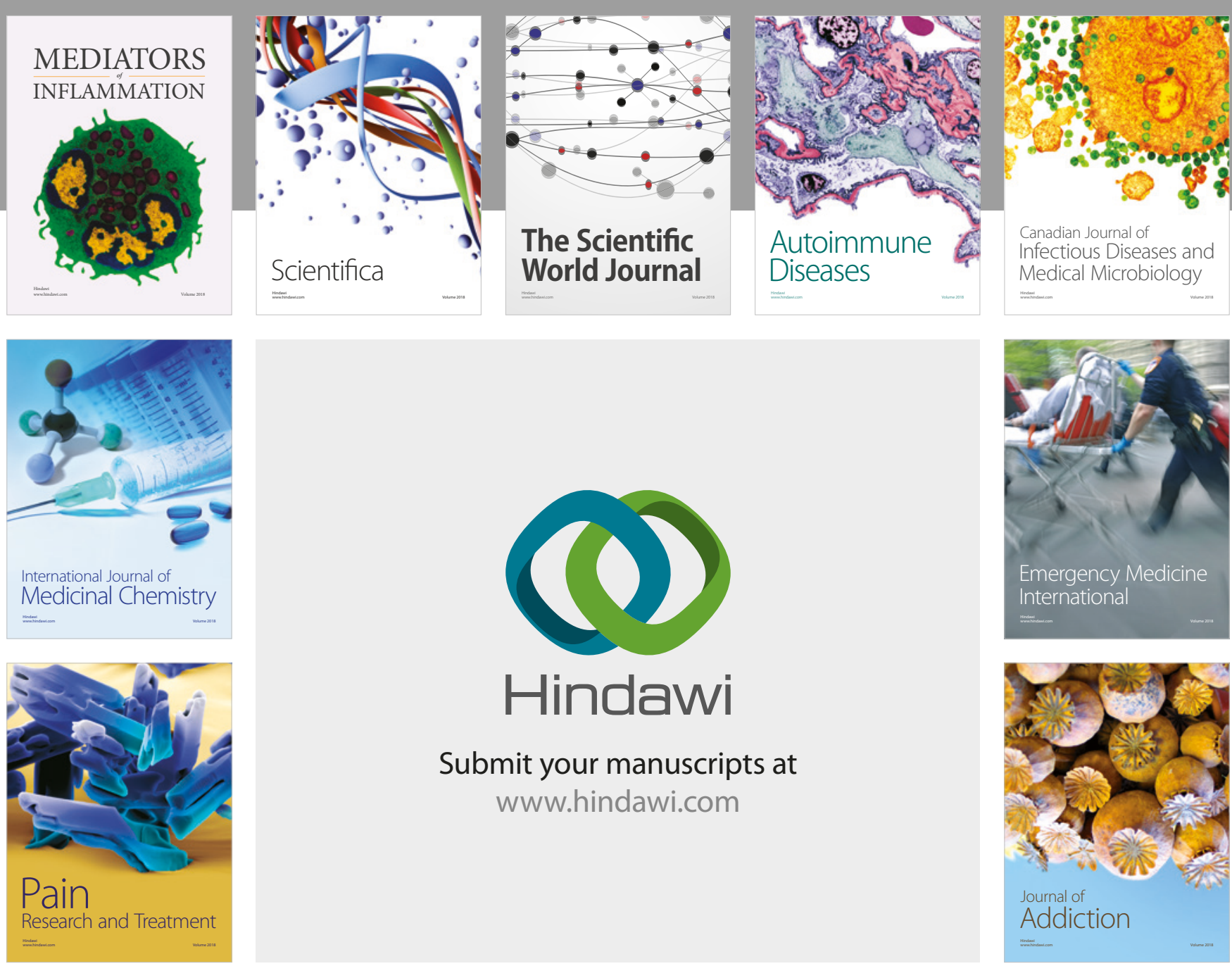

Canadian Journal of
Infectious Diseases and Medical Microbiology

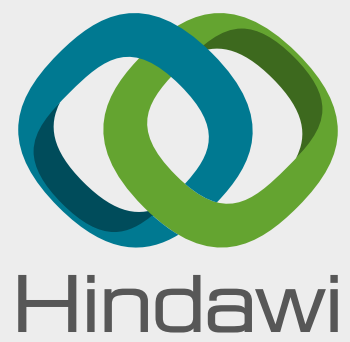

Submit your manuscripts at

www.hindawi.com
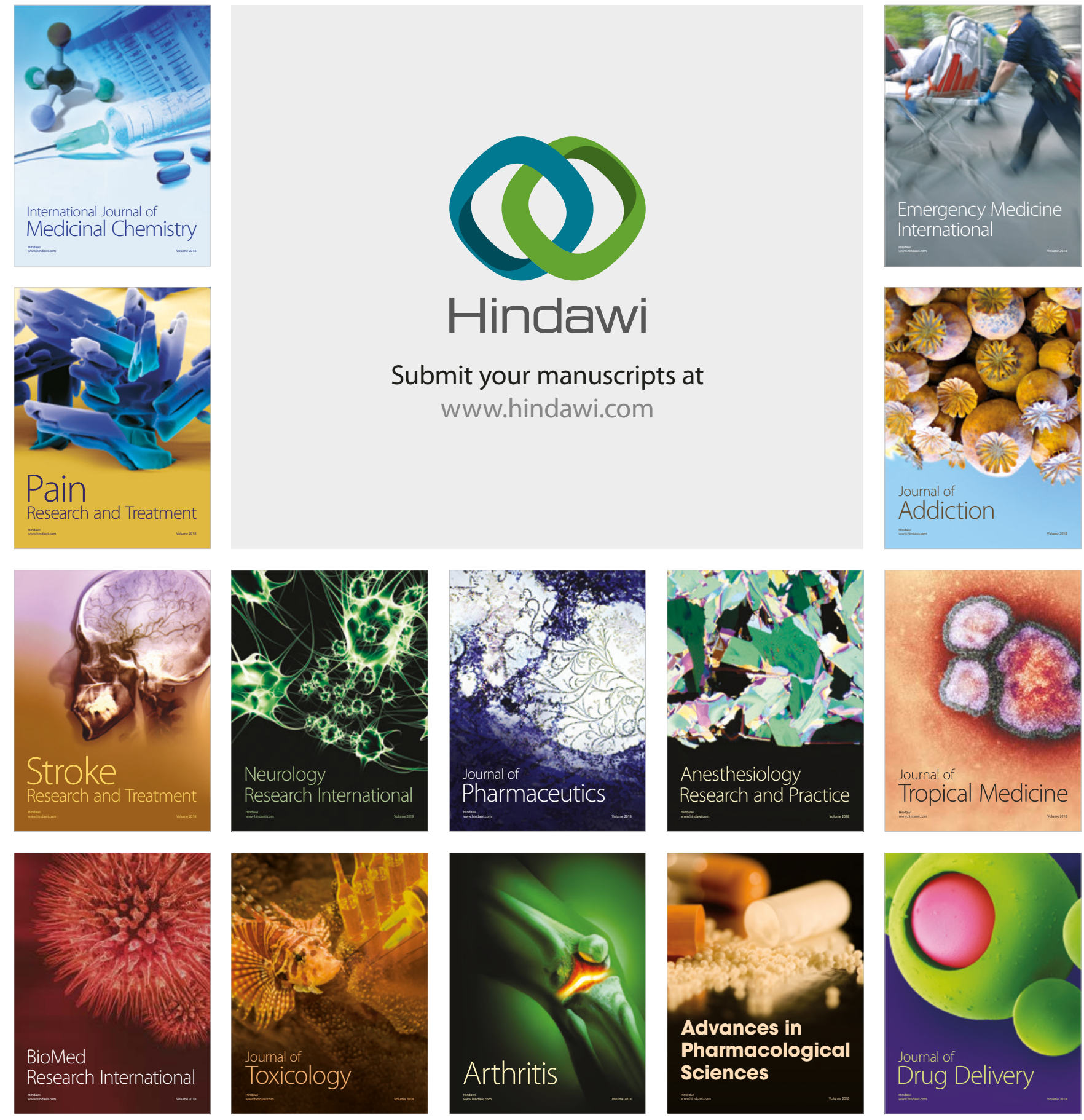